American Journal of Applied Sciences 9 (8): 1188-1193, 2012

ISSN 1546-9239

(C) 2012 Science Publications

\title{
Impact of Training Program to Rationalize Consumption of Domestic Water Usages
}

\author{
Mohammad Said Damanhouri \\ Department of Finance and Administrative Sciences, \\ Princess's Alia University College, Al-Balqaa' Applied University, Amman 11194, Jordan
}

\begin{abstract}
Problem statement: Reducing water consumption in terms of scarcity of water in Jordan which needs to rationalize consumption of the domestic water usages by some families in AmmanJordan. Approach: This study aimed to decrease water consumption in household usages and to involve and encouraging the pioneer students in voluntary efforts to reduce domestic water. The study sample consisted of 121 female students of Princess' Alia University College represented 121 Jordanian families in Amman. They trained to reduce flow of water and the time during usage water in kitchen; toilet; bathroom; washing cars; and to put a plastic bottle full of half liter of water in the toilet's water tank. Economical and social variables of families were obtained from special questionnaire of this study, data were formed from previous measurements and information; the data analyzed throughout a simple statistical approach. Results: The families whom represented this study sample have positively responded for the proposed program; through reducing water consumption in domestic usages. The most important factor effects on rationalized water consumption are: Average monthly income, average family members, average of family members ages, the size of water tank of the toilet, size of shower used. Conclusion/Recommendations: The study concluded that the amount of preserved water in a bathroom may reach $25 \%$, in kitchen 29 , in toilet $10 \%$, in washing cars $9 \%$, of water consumption before implementation program at each of the previous sectors. The total amount of preserved water in Amman may reach to 11 million cubic meters annually. The study recommends implementing this simple program on the whole of Jordanian families as much as possible and encouraging the Jordanian citizens to use different tools, means, programs that may control water consumption and to recycle the used water as possible.
\end{abstract}

Key words: Social variables, field measurements, amman may, preserved water, water deficit, different tools, monthly consumption

\section{INTRODUCTION}

Water is the most important necessary substance of human's life. Many human civilizations have been established in different river valleys simply because of the existence of water. Therefore, there is a strong need for a new approach of using water wisely in the Arab region. It is so because of the scarcity of water and the developmental and housing need for water. Scientific researches should be intensively conducted to reach technological achievements to meet the several demands for water.

The importance of water has been increasing recently because of the increase in the global demand for it, which has led to regional conflicts to get it, so that each country may achieve water security for its people (Hassan, 2011).
The average consumption of water differs from one individual to another, not only in different countries but also in the same country. It also varies in different seasons. The universal average of the individual consumption of water is $1240 \mathrm{~m}^{3}$ annually, but falls down to $250 \mathrm{~m}^{3}$ in countries with poor water resources (Damanhouri, 2010).

Globally, Jordan has been ranked the fourth poorest country with its water resources. This is due to its natural circumstances and landscape. This is obvious in the fact that almost $80 \%$ of its land is located in dry regions, that gets an average of only $350 \mathrm{~mm}$ of rain water annually, $90 \%$ of this average evaporates. Jordan's scarcity of water is also because of the fact that it lacks any sort of surface water likes seas or rivers except for a small bay of the Aqaba Gulf on the Red Sea and very small river (Jordan River). The serious impact of this water poverty has emerged with the 
population explosion that has been raised as a result of the obligatory immigration by people from the neighboring countries. Consequently, the water deficit in the water budget has rapidly and seriously increased. It has reached to $41 \%$ of the water required for agriculture, industry and domestic use (Damanhouri, 2010).

This has led to focusing on the importance of reducing water consumption in order to benefit from water to the most, by using fewer quantities with less cost. Actually, reducing water consumption has become a national duty especially when it comes to domestic usages of water in different areas at homes such as: the kitchen, the toilet, the bathroom and car wash, simply because these usages constitute about $90 \%$ of domestic water usages (IRIN, 2008).

Many previous studies reveal that water house consumption as; Damanhouri (2010); Otaki (2009) and Shahateet (2008).

\section{MATERIALS AND METHODS}

This study aims to reveal the amount of the preserved water for this simple training program. And to forming positive attitudes in the process of water consumption in houses. It also aims to involve and encouraging the pioneer students in voluntarily effective group-works to reduce domestic water consumption.
The sample of the study was 121 female students of Princess Alia University College, that represented 121 Jordanian families in Amman. These students were trained to reduce the average of water flows and to reduce the time of water flows during using the water in the kitchen, the toilet, the bathroom and car wash with the hose. They were asked to put a plastic bottle full of half a liter of water in the toilet's water tank. Each student calculated the amount of water that was consumed by her family both before the implementation of the program and after.

The database of this study is formed of field measurements of the amount of water consumed in the students' houses and from Special questionnaire was prepared to get information about both economical and social variables. This questionnaire was prepared to know information such as the monthly income for each family and the number of the family members was also revealed by the items on the questionnaire. Therefore, these different variables that are expected to affect the rationality of domestic water consumption have been arranged in lists 1-4 below.

In light of the amount of the monthly consumption of water, the sample of the study was classified into three categories as illustrated in the following Table 1.

List 1: Variables affecting the water consumption in Kitchen, before and after the implementation of the program

Number of members of the family

Average of family monthly income (JD) per month

A number of tools used in preparing and having the three meals before and after the implementation of the program

The average of the amount of water flowing down from the tabs liter per minute (L/min) while washing up after each meal before and after the implementation of the program

Time needed to wash up the tools and the dishes after each meal before and after the implementation of the program (minutes)

List 2: Variables affecting the water consumption in Bath room by using shower and bath tub, before and after the implementation of the program

Number of members of the family

Average of ages of family members

Average of family monthly income (JD) per month

How many times members of the family take a bath every week

How many times members of the family take a bath using the shower every week

The amount of water (liter per minute) that flows from the shower while taking a bath before the implementation of the program

The amount of water (liter per minute) that flows from the shower while taking a bath after the implementation of the program

The duration of taking a bath using the shower before the implementation of the program. (minute)

The duration of taking a bath using the shower after the implementation of the program (minute)

How many times members of the family take a bath in the bath tub every week

The amount of water in the bath tub before the implementation of the program (liter)

The amount of water in the bath tub after the implementation of the program(liter)

List 3: Variables affecting the water consumption in toilets, before and after the implementation of the program

Number of members of the family

Average of ages of family members

Average of family monthly income (JD) per month

Numbers of daily usages of the toilet by the members of the family

The amount of the water in the toilet's water tank before the implementation of the program (liter)

The amount of the water in the toilet's water tank after the implementation of the program (liter) 
List 4: Variables affecting the water consumption in washing cars, before and after the implementation of the program

Number of members of the family

Average of ages of family members

Average of family monthly income (JD) per month

Number of cars owned by each family

Number of weekly car wash

Number of weekly car wash using a bucket

The amount of water consumed to wash the car using a bucket (liter)

Number of weekly car wash using a hose

The average of the amount of water that flows from the hose before the implementation of the program (liter per minute)

The average of the amount of water that flows from the hose after the implementation of the program (liter per minute)

The duration of a single car wash using the hose before the implementation of the program (minute)

The duration of a single car wash using the hose after the implementation of the program (minute)

The amount of the water consumed weekly to wash the car using a hose before the implementation of the program (liter)

The amount of the water consumed weekly to wash the car using a hose after the implementation of the program (liter)

Table 1: Studied sample frequency distribution

\begin{tabular}{lclr}
\hline Group & Frequency & Average consumption & $(\%)$ \\
\hline A & 9 & $>15\left(\mathrm{~m}^{3} /\right.$ month $)$ & 7.4 \\
B & 52 & $10-15\left(\mathrm{~m}^{3} /\right.$ month $)$ & 43.0 \\
C & 60 & $<10\left(\mathrm{~m}^{3} /\right.$ month $)$ & 49.6 \\
Total & 121 & & 100.0 \\
\hline
\end{tabular}

\section{RESULTS AND DISCUSSION}

The result of analyzing data on the frequency of distribution has shown that there has been a positive response from all categories of the sample of this study. They have responded positively to the program this can be detected from the amount of the preserved water that has reached to 11 million cubic meters annually, of the consumed water used in housework by families living in Amman. The results also show that this amount of preserved water is distributed at not less than $90 \%$ of water consumption used for domestic purposes. These aspects that reflect the consumption of water preservation are as follows:

The preserved water while in the kitchen is $3.2(\mathrm{~m}$. $\left.\mathrm{m}^{3}\right)$, in the bathroom $5.7\left(\mathrm{~m} . \mathrm{m}^{3}\right)$, in the toilet $1.1(\mathrm{~m}$. $\left.\mathrm{m}^{3}\right)$ and car-wash $1\left(\mathrm{~m} . \mathrm{m}^{3}\right)$, annually.

Compared to the scarcity of water in Jordan, these amounts of preserved water form a valuable ratio. This fact motivates the implementation of this simple proposed program by all Jordanian families. Once done, this implementation is expected to preserve $22 \mathrm{~m} . \mathrm{m}^{3}$ of wateranually. This is particularly true since the number of population in Amman equals half of the number of the population of the whole kingdom which was estimated to be 6 million in 2006 .

The impact of the implementation of the program on the water consumed in the kitchen: The results of data analysis of the amount of water used in the kitchen before and after the program shows that there is a reversed relation between the amount of preserved water on one hand and the monthly average of the family consumption of water, the average of the family monthly income, number of the members of the family, average of the ages of the members of the family and the number of the tools used preparing for and having the three meals on the other hand.

As can be shown in Tables 2-4 the average of the water that is monthly preserved by the individual person over the three meals: breakfast, lunch and dinner has reached to 21,30 and $35 \mathrm{~L}$ daily, respectively. Taking into consideration the number of the population living in Amman as mentioned above, the amount of the preserved water over the three meals reaches to 0.8 $\left(\mathrm{m} . \mathrm{m}^{3}\right), 1.1\left(\mathrm{~m} . \mathrm{m}^{3}\right)$ and $1.3\left(\mathrm{~m} . \mathrm{m}^{3}\right)$ that is 3.2 million cubic meters altogether per year.

As it is clearly seen in Table 5, the results also show that the largest amount of preserved water is the one preserved over dinner while the smallest is that preserved over breakfast. This is so because of the fact that people usually have their breakfast at home unlike dinner that is taken either as ready take- away meals from fast food restaurants or is taken in cafés and restaurant outside. As for the lunch meal, it is still culturally taken by the whole family at homes.

The impact of the implementation of the program on water consumed in the bathrooms: As can be seen from Table 6 , the amount of the preserved water in the bathrooms increased as long as there is an increase in the average of the monthly consumption of water, the average of the monthly income of the family, the average of the number of the family members and the average of the ages of the family members.

The amount of preserved water by the three categories of the sample has reached to 249, 167 and 68 liter respectively. This accumulates to a relative amount of $161 \mathrm{~L}$ per person per month or $1.9 \mathrm{~m}^{3}$ year $^{-1}$. Consequently, the amount of the preserved water in the bathroom may reach to 5.7 (m. $\mathrm{m}^{3)}$ per year in Amman. Once this program is implemented by all Jordanian families, the amount of water that is expected to be preserved may get to $11.4\left(\mathrm{~m} . \mathrm{m}^{3}\right)$ a year in Jordan.

The highest percentage of the preserved amount of water used for all purposes (10\%) is shown in the first category of the sample. That is to say the one with the highest average of monthly income. 
Am. J. Applied Sci., 9 (8): 1188-1193, 2012

Table 2: Relation between family monthly income, water consumption and water savings at breakfast

\begin{tabular}{lcccccrr}
\hline Group & $\mathrm{R}(\mathrm{L})$ & $\mathrm{B}(\mathrm{JD})$ & $\mathrm{C}$ & $\mathrm{D}$ & S.W/CAPITA & AV.M.W.C $\left(\mathrm{m}^{3}\right)$ & sav. \% \\
\hline A & 170.0 & 1672.2 & 9 & 25.2 & 15 & 22 & 0.6 \\
B & 240.0 & 854.2 & 8 & 22 & 19 & 16 & 1.0 \\
C & 266.9 & 613.3 & 7 & 21 & 29 & 12 & 1.7 \\
& & & & & Average & 17 \\
\hline
\end{tabular}

Table 3: Relation between family monthly income, water consumption and water savings on lunch

\begin{tabular}{|c|c|c|c|c|c|c|c|}
\hline Group & $\mathrm{R}(\mathrm{L})$ & $\mathrm{B}(\mathrm{JD})$ & $\mathrm{C}$ & $\mathrm{D}$ & S.W/CAPITA & AV.M.W.C (m3) & sav. $\%$ \\
\hline $\mathrm{A}$ & 248 & 1672 & 12 & 27 & 21 & 22 & 0.1 \\
\hline B & 285 & 854 & 9 & 25 & 33 & 16 & 0.1 \\
\hline $\mathrm{C}$ & 293 & 613 & 8 & 22 & 35 & 12 & 0.2 \\
\hline & & & & & Average & 17 & 0.1 \\
\hline
\end{tabular}

Table 4: Relation between family monthly income, water consumption and water savings at dinner

\begin{tabular}{lccccccc}
\hline Group & $\mathrm{R}(\mathrm{L})$ & $\mathrm{B}(\mathrm{JD})$ & $\mathrm{C}$ & $\mathrm{D}$ & S.W/CAPITA & AV.M.W.C (m3) & sav. \% \\
\hline A & 1672 & 9 & 25 & 28 & 28 & 21.5 & 1.1 \\
B & 852 & 8 & 22 & 36 & 36 & 16.4 & 1.7 \\
C & 613 & 7 & 21 & 42 & Average & 1.7 & 1.5 \\
& & & & & & & 1.5 \\
\hline
\end{tabular}

Table 5: Relation between family water consumption and water savings at breakfast, lunch and dinner

\begin{tabular}{llll}
\hline AV.M.W.C(m3) & B.sav. \% & L.sav. \% & D.sav.\% \\
\hline 22 & 0.6 & 1.1 & 1.1 \\
16 & 1.0 & 1.8 & 1.7 \\
12 & 1.7 & 2.4 & 2.5 \\
Legend & B: Breakfast & L: Lunch & D: Dinner \\
\hline
\end{tabular}

The lowest percentage of the preserved amount of water used for all purposes (4\%) is shown in the third category. This clarifies what has been mentioned earlier that the amount of the preserved water in the bathroom increases as the amount of the water consumed in the bathroom increases every month. This is because the number of taking a bath by families of category number one is three times more than the number of taking a bath by the families of category three (with the lowest income). These results comply with the documents issued by the Ministry of Water and Irrigation. Those documents noted that families living in West Amman (families of category one with the highest monthly income) consume $74 \%$ of the water in housework. While, families of second and third categories consume the remaining $26 \%$ amount of the water in the housework.

The impact of the implementation of the proposed program on water consumed in the toilet: The means of reducing the consumption of water in the toilet are mainly by putting a half liter-sized plastic bottle filled with water and closed tightly in the toilet's water tank. Doing so, it is guaranteed that the amount of water to be used every time the toilet is flushed will be less than the amount of water flushed out of a tank without the bottle of water. The amount of the preserved water increases as the average of the family members, the average of the ages of the members and the average of the family monthly income decrease.

Table 7 shows that the amount of the preserved water from the individual person of the first category (the rich one) reaches 25 liters per month, while the amount of the preserved water from the individual person of the third category (the poor one) reaches to $34 \mathrm{~L}$ per month. Generally speaking, the average of the amount of the water preserved by an individual person of each category reaches to $30 \mathrm{~L}$ per month that means 360 liters per year. As a result, the implementation of this proposed program in the toilets by all families living in Amman may result in preserving $1.1\left(\mathrm{~m} \cdot \mathrm{m}^{3}\right)$ yearly. The results of data analysis also show that of the water consumed for all domestic purposes, $20 \%$ is consumed in the toilets by rich families, while $53 \%$ is consumed by poor families. This discrepancy can be explained by virtue of the large amount of water that is wasted in case there is a technical problem with the toilet water tank. This technical failure may be immediately fixed by rich families but ignored or postponed by poor families. This delay or ignorance is mainly because of the fact that poor people are less aware of the importance of water in daily life. Another reason might be the longest duration that poor people spend at homes as compared to the shorter duration rich people spend in their homes.

The impact of the implementation of the proposed program on consumed water used to wash cars: The results of data analysis of water consumption before and after the implementation of the program reveals a relation between the average of the preserved water used to wash cars on one hand and the average of the family monthly income and the average of the consumed water on the other (Table 8). The average of the preserved water has ranged between 23 liter and 30 liter per month and per person with an average of 26 liter per person, that is to say an average of $1.3 \%$ of preserved waters for all groups. This gives an average of one $\left(\mathrm{m} . \mathrm{m}^{3}\right)$ per year in Amman. It is also indicated that the poor people's positive response in the preservation of the water used to wash the cars is higher than that of the rich people. 
Am. J. Applied Sci., 9 (8): 1188-1193, 2012

Table 6: Relation between family monthly income, water consumption and water savings in the bathrooms

\begin{tabular}{|c|c|c|c|c|c|c|c|}
\hline Group & $\mathrm{R}(\mathrm{L})$ & B (JD) & $\mathrm{C}$ & $\mathrm{D}$ & S.W/CAPITA & AV.M.W.C $\left(\mathrm{m}^{3}\right)$ & sav. $\%$ \\
\hline $\mathrm{A}$ & 18 & 1672 & 9 & 25 & 249 & 22 & 10 \\
\hline B & 12 & 854 & 8 & 22 & 167 & 16 & 8 \\
\hline \multirow[t]{2}{*}{$\mathrm{C}$} & 7 & 613 & 7 & 21 & 68 & 12 & 4 \\
\hline & & & & Average & 161 & 17 & 7 \\
\hline Group & $\mathrm{R}(\mathrm{L})$ & $\mathrm{B}(\mathrm{JD})$ & $\mathrm{C}$ & $\mathrm{D}$ & S.W/CAPITA & AV.M.W.C $\left(\mathrm{m}^{3}\right)$ & sav. $\%$ \\
\hline A & 2 & 20 & 9 & 25 & 25 & 22 & 1.0 \\
\hline B & 3 & 16 & 8 & 22 & 31 & 16 & 1.5 \\
\hline \multirow[t]{2}{*}{$\mathrm{C}$} & 2 & 9 & 7 & 21 & 34 & 12 & 2.0 \\
\hline & & & & & Average & 17 & 1.5 \\
\hline
\end{tabular}

Table 8: Relation between family monthly income, water consumption and water savings in washing cars

\begin{tabular}{llllllll}
\hline Group & $\mathrm{R}(\mathrm{L})$ & $\mathrm{B}(\mathrm{JD})$ & $\mathrm{C}$ & $\mathrm{D}$ & S.W/CAPITA & AV.M.W.C $\left(\mathrm{m}^{3}\right)$ & sav. \% \\
\hline A & 2.1 & 16.7 & 9 & 25 & 23 & 22 & 0.9 \\
B & 2.0 & 8.5 & 8 & 22 & 24 & 16 & 1.2 \\
C & 2.2 & 6.1 & 7 & 21 & 30 & 12 & 1.8 \\
& & & & Average & 26 & 17 & 1.3 \\
\hline
\end{tabular}

This can be explained by the more cars owned by the rich families as compared to the number of cars owned by the poor. In addition, those who are in charge of cleaning rich people's cars are mainly hired by those families. These hired workers are not really concerned with the value of the water bill this makes them use the hose that is kept in use throughout the whole washing process without caring about the amount of water flowing from the hose. In comparison, poor families wash their cars themselves. Because they are worried and concerned about the value of the water bill, they usually use a bucket which leads to a less consumption of water.

This study shows the following results:

- The families, whom presented the sample of the study, have positively responded to the proposed program to reduce water consumption in the domestic usages. This can be clearly inferred from the amount of preserved water( $11 \mathrm{~m} . \mathrm{m} 3)$ yearly, that resulted from the implementation of the program by those families in Amman

- The amount of preserved water in the bathroom may reach to $52 \%$ of the total amount of the preserved water referred to earlier. On the other hand, in the kitchen, water may be preserved with a ratio of 29 ; $10 \%$ in the toilet and $19 \%$ of the total amount of the preserved water is preserved in a car wash

- The most important factors that may influence the process of rational water consumption are: the monthly average of the amount of water consumed for domestic purposes by each family, the average of the family monthly income, the average of the family members, the average of the ages of the family members, the size of the water tank in the toilet, the size of the shower used in the bathroom and finally the average of water that flows from the tabs, the shower and the hose,. In addition to its duration

- The amount of water that is consumed for domestic purposes increases as the average of family monthly income increases. To put it differently, families of the first category with the highest average of income who live in the west and north parts of Amman consume about $74 \%$ of the total amount of water used for domestic purposes

\section{CONCLUSION}

- The study concluded that Jordan can preserve the amount of water reached to $\left(22 \mathrm{~m} . \mathrm{m}^{3}\right)$ yearly Of water consumed in domestic usages, if this simple proposed program confined and used across the kingdom

- The study concluded that the value of the operational cost of the amount of preserved water is $11\left(\mathrm{~m} . \mathrm{m}^{3}\right)$ that is equal about 14.3 million Jordanian Dinars. This amount of money can be invested to develop and improve managing the demands for water or other productive projects in Jordan

Recommendations: This study recommends the followings:

- Implementing this simple proposed program to control the consumption of water used for domestic purposes in other areas in the country to include as a larger number of Jordanian families as possible

- Encouraging the Jordanian citizens to use different tools, means and programs to control the consumption of water 
- Encouraging positive approaches in this regard to create social and rational attitudes towards the issue of preserving water and handling it with great care

- Controlling the import of machines, appliances and devices that require more amount of water to be used in the kitchens, bathrooms and/or the toilets

- Controlling the consistent increase in the consumption of water by the first group of (rich people); even though, they are able to pay the very high water bills. This is because water is one of the national resources and any deficit or scarcity in this resource would definitely lead to a deficit in the water budget which would put the national security in jeopardy

- Encouraging the citizens to recycle the used water in the kitchen or the bathroom, this leads to a reduction in the amount of water that is monthly consumed by the Jordan family

- $\quad$ Supporting and encouraging research that investigates means of controlling the consumption of water in all aspects of life. Such studies would have a positive impact on the reduction of the water deficits that is one of the very crucial problems in Jordan

\section{REFERENCES}

Damanhouri, M.S., 2010. Effect of raising the environmental awareness on reducing kitchen water consumption in the kitchen. Am. J. Applied Sci., $\quad 7$ : $1123.1128 . \quad$ DOI: 10.3844/ajassp.2010.1123.1128

IRIN, 2008. Water rationing strategy to combat shortages. IRIN.

Otaki, 2009. Micto-components survey of residential indoor water consumption in chiang Mai. drink Water. Eng. Sci., 1: 45-70. DOI: 10.5194/dwesd-145-2008, 2008

Shahateet, M.I., 2008. An Econometric model for water sector in Jordan. Am. J. Soc. Sci.

Hassan, G., 2011. The role of woman in water consumption. 